\title{
The Scholarship of College Teaching: Research Opportunities in the New Millennium
}

\author{
Roger Fisher \\ Fanshawe College
}

\begin{abstract}
This paper examines some of the challenges facing contemporary Canadian community colleges and explores research opportunities related to (a) measuring the effectiveness of college teaching, (b) preparing beginning college teachers, and (c) re-conceptualizing professional development programs. First, the criteria for measuring teaching effectiveness at colleges are often derived from those used in elementary and secondary schools; questions remain as to whether, or to what degree, these criteria are appropriate measures of effective teaching in the college setting. Second, unprecedented retirements are creating an influx of beginning faculty with extensive subject expertise but often with little or no training as professional teachers; while traditional mentorship models often function as in-house induction programs, innovative pre-service training programs are being developed to more fully prepare aspirants to the profession of college teaching. Finally, some colleges are re-conceptualizing their professional development programs, employing innovative models such as Teaching Circles which are designed to build communities of scholars focused on institutional excellence in teaching. Numerous opportunities exist for research into teaching effectiveness, faculty induction, and professional development amid the changes and challenges that currently face the community colleges.
\end{abstract}

\section{Introduction}

"The times they are a-changin'," in the famous words of Bob Dylan, on the campuses of Canada's community colleges. Student demographic profiles and educational expectations are shifting. Unprecedented faculty retirements are creating a huge influx of largely untrained new teachers. All of this is occurring in the context of a dramatic re-visioning of professional development programs for college faculty. As a professor at a Canadian community college, I find this dawn of a new millennium an opportune occasion to re-assess the "scholarship of teaching" (Boyer, 1990) in the context of Canadian community colleges and to explore current opportunities for research, especially with regards to teaching effectiveness, faculty induction, and professional development programs. This paper examines three critical research questions in particular: First, what teaching practices most effectively meet the needs of today's diverse college students? Second, how will colleges help prepare beginning faculty to navigate their

Roger Fisher is a Professor in the General Studies Division at Fanshawe College in London Ontario. His interests include professional development and building applied research cultures at community colleges. He is currently pursuing his $\mathrm{PhD}$ in Educational Studies. 
transition from subject-expert to adult educator? Third, how will colleges prepare beginning and experienced faculty to develop a "community of scholars" (Boyer, 1990), infused with "strong professional cultures of collaboration" (Hargreaves \& Fullan, 2000)? Through exploring these research questions, I hope to articulate more clearly a scholarship of college teaching which has resonance with and application to the challenges and changes facing today's community colleges.

\section{Qualities of Effective Teaching}

What teaching practices will most effectively meet the needs of contemporary college students? A review of the extensive research into effective teaching characteristics in elementary and secondary schools provides a starting point for identifying those common qualities that will most benefit the diversity of ages, interests, and abilities of contemporary college students.

In The Qualities of Effective Teachers, Stronge (2002) conducted a comprehensive, comparative analysis of twenty-six international and American (national and state-wide) studies of the qualities, characteristics, and practices of "effective teachers" (p. vii) in elementary and secondary settings. In one such study, conducted by the National Association of Secondary School Principals (1997), students identified their "top five characteristics of the best" (p. 112) teachers. According to these secondary school students, effective teachers "have a sense of humor; make the class interesting; have knowledge of their subjects; explain things clearly; [and] spend time helping students" (pp. 112-113). Another American study (Johnson, 1977) conducted widespread interviews with teachers, principals, and board members from urban, suburban, and rural schools, to provide an "analysis of multiple perspectives of effective teaching" (p. 107). Results indicated commonalities of effectiveness in "instructional strategies, identification of lesson objectives, monitoring and assessing students, studentcenteredness, [and] positive learning environment" (pp. 107-8). Johnson concluded that "effective teaching involves a two-way communicative process initiated by a teacher who is well versed in the subject matter, caring, and able to establish and maintain classroom control" (p. 108). A more recent British study (McBer, 2000) concluded that "effective teachers have extensive content knowledge and possess a bank of appropriate teaching strategies [that] interact to create a classroom climate conducive to learning" (p. 110). A similar study by Hawk (1985) supports the same conclusion that "the factors of content knowledge and instructional strategies ... combine to increase student achievement" (p. 106). In summary, according to Stronge's (2002) analysis of these 26 studies, effective teachers:

1. Establish environments of respect, in which all students feel physically and emotionally safe, and where their opinions and contributions are invited and valued;

2. care about their students' success and motivate them to high expectations;

3. set clear expectations, and provide clear metrics as to how those expectations will be assessed;

4. make coursework relevant and significant to students' lives beyond the classroom; 
5. perceive students as active participants in, rather than passive recipients of, learning;

6. utilize a variety of teaching strategies and learning activities to engage and motivate students to achieve success;

7. provide on-going feedback to improve student performance;

8. exude enthusiasm, demonstrate humour, and make learning fun (pp. 71-76).

While extensive research has identified a number of "commonalities" (Stronge, p. viii) among effective teachers in elementary and secondary settings, the question remains as to whether, or to what degree, these characteristics of effective teaching are transferable to a college setting.

\section{Effective teaching at community colleges}

In contrast to the extensive research in elementary and secondary setting, far less attention has been paid to measuring teaching effectiveness at the college level. One Canadian study (Lowry \& Froese, 2001) found "a paucity of Canadian research into community colleges, and even less into the effectiveness of instruction at these institutions.... It is striking how little research into the quality of teaching is taking place in institutions that purport to have a focus on teaching" (p. 3). To review relevant research in this area, it is, therefore, necessary to examine several American studies which have attempted to address this issue. For example, in a study by Van Ast and Mullen (1999), the characteristics of effective college teaching at American colleges included: caring about students, expressing high expectations of students' self-worth, relating course content and value to real-life situations, allowing students to take responsibility for their own learning, setting clear expectations and objectives, incorporating students' experiences into lessons, providing effective feedback, and motivating for success. In another study (Higgins \& Hawthorne, 1994) of "the successful community college instructor" (p. 27), the researchers asked 130 Chief Academic Officers in three U.S. states to identify exceptional full-time college faculty, of whom 289 completed questionnaires, surveys, and on-line interviews. When these teachers were asked to specify their personal strongest assets, "concern for students and an ability to work with students possessing a wide range of abilities" (p. 30) were most frequently noted. Specific qualities mentioned were patience, sense of humor, knowledge of the adult learner, flexibility, communication skills, and respect for and availability to the students. Higgins and Hawthorne concluded that "the most important quality or characteristic of successful community college instructors is a genuine interest in working with a diverse student clientele. Success in teaching appears to be focused as much on the interaction with students, as on the transmission of course content" (p. 31). Another American study (Galbraith \& Shedd, 1990) similarly concluded that effective college teachers "must possess personality characteristics and interpersonal skills that engender an image of caring, trust, and encouragement" (p. 8). Apps (1981) similarly found that the best qualities for the college instructor were those "that showed an interest in the students [and] had the ability to make the subject interesting" (p. 3). 
Though little research exists in the context of Canadian community colleges, some indication of administrators' expectations of teacher effectiveness may be found in the criteria used in Fanshawe College's Professor Performance Review Program (2002); some of the identified indicators of an effective college teacher include:

1. Displays courtesy and respect;

2. designs learning activities which actively engage and challenge students;

3. clearly states objectives and directions;

4. relates content to real-life situations beyond the classroom;

5. uses enthusiasm, energy, and optimism to motivate students;

6. expresses high/realistic expectations that students can achieve;

7. invites and respects different opinions (pp. 12-14).

Similar criteria of effectiveness are used at the same college in its Instructional Feedback Survey, in which students complete Likert scales to rate their professors' performances. Based on indications inferred from these criteria, it appears that college administrators are assuming that the qualities of effective teaching identified by Stronge (2002) in elementary and secondary settings are congruent with college expectations. Opportunities, therefore, exist to test these assumptions, specifically regarding the expectations of contemporary college students and the appropriateness of the (elementary and secondary) measures and indicators currently used on college campuses.

Not only would research contribute to the clarification of appropriate criteria for the measurement of teaching effectiveness, it could also inform the design and implementation of professional development programs for the induction of a new generation of college teachers. This addresses the second critical research question as to how colleges can assist newly hired faculty in their transition from subject-expert to adult educator. The next section examines two current but contrasting models for inducting beginning college teachers, namely, innovative pre-service programs and traditional mentoring models.

\section{Effective Induction of Beginning Teachers}

At the end of the twentieth century, a combination of demographic forces is creating conditions of urgency which demand innovative responses to the task of inducting beginning teachers. In Preparing Community College Faculty for the New Millennium, Miller (1997) predicts that "as the children of the baby boomers reach college age, an enrollment surge is inevitable; at the same time, large numbers of faculty will approach retirement" (p. 1). Canadian colleges face the same critical challenge as their American counterparts. "Needless to say," writes Cheryl Simpson, Vice President of Human Resources at Georgian College in Barrie, Ontario, "we have a significant challenge ahead of us" (Ontario Colleges Face Hiring Crunch, 2001, p. 1). Central to that challenge is the fact that the majority of beginning college faculty lacks even a modicum of professional teaching training. Keim (1989) found less than one-third of college instructors had taken a single course in community college teaching. Galbraith and Shedd (1990) note similarly that most college instructors "are expert in the content they 
teach, but they usually have little preparation in the process of helping adults learn ... over $53 \%$ of part-time faculty had no training in adult education, [and] $63 \%$ had no formal teacher training of any type. In far too many instances, teaching assignments are given to people not equal to the task. The instructor may know the subject, but lack teaching skills" (p. 7). As noted by O'Banion (1974), "if the primary expectation for community college faculty is that they will teach, it seems reasonable to expect that considerable institutional resources will be directed toward developing faculty's basic instructional methodology skills" (p. 4). In the previous review of teaching characteristics, at least two studies (Hawk, 1985; McBer, 2000) identified a combination of both subject and instructional expertise as essential characteristics of effective teaching. In the context of the Canadian community college system, whose mandate is the preservice training and certification of a skilled, professional workforce (Ontario Colleges of Applied Arts and Technology Act, 2002) and whose instructors are recruited primarily for their subject (rather than teaching) expertise, this need to provide training for beginning faculty is especially critical. Unfortunately, while extensive programs of pre-training and certification exist for elementary and secondary school teachers, few similar programs are currently provided for beginning teachers entering the Canadian community college system. Signs of progress, however, in the form of innovative pre-service programs for college faculty, are on the horizon.

\section{Pre-service programs for college faculty}

The issues and concerns surrounding pre-service preparation and certification of college faculty have changed little since the inception of community colleges (Miller, 1997). O'Banion (1974) noted that, with few exceptions, pre-service educational programs for college teachers in the United States were "grossly inadequate [and] unable to meet the needs for recruiting new community college faculty, and renewing existing faculty" (p. 10). Over twenty years later, O'Banion (1994) continued to call for professional pre-service training and certification as "the changing student population, advancing technology, and educational ideologies such as outcomes assessment combine to create a more complex teaching environment for today's instructor" (p. 5). Miller (1997) summarizes the situation of pre-training and certification for college faculty in the United States at the end of the twentieth century:

Community college teaching has emerged as a distinct profession. It requires a preparatory program that will instill the knowledge and skills needed for effective faculty members, and provide the philosophical grounding and socialization required for a role that has become more complex over the years.... A key question continues to be whether efforts and expenditures should be directed toward pre-service rather than to in-service programs, which appear to have low participation rates by the faculty most in need of them.... Community college leaders must insist that college and university pre-service programs become responsive to their needs. (p. 88)

Fortunately, in the context of Canadian community colleges, professional training and certification programs for college instructors are beginning to 
appear. For example, in the province of British Columbia, the Ministry of Skills, Training and Labour now offers a Provincial Instructor's Diploma Program (1999) which provides current college faculty and those intending to enter the profession with opportunities "to acquire and develop instructional expertise [and] competencies in the design, management, and evaluation of instruction of adults. ... The Provincial Instructor's Diploma is for every adult educator in public post-secondary ... who is committed to excellence in teaching and learning" (p. 1). Similarly, the province of Nova Scotia has instituted a Community College Education Diploma Program (Lowry \& Froese, 2001) "to help new faculty become more effective instructors while making the transition to a new occupation" (p. 2). Successful completion of the Nova Scotia Community College Education Diploma Program is now a condition of employment for all new faculty and professional support staff, and is a mandatory requirement for current faculty to move from probationary to permanent status. In their study of this program, Transitions: Becoming a College Teacher, Lowry \& Froese (2001) concluded that the Nova Scotia Community College Education Diploma Program:

\begin{abstract}
... despite its short history, is very much part of trends in evidence among community colleges in North America. Faculty at Nova Scotia Community College ... recognize the need for training in order to become effective instructors .... Focusing institutional resources on training instructors must be a priority if instruction is to be improved and the institution is to be seen as accountable for one of its key goals, which is to foster learning. (pp. 10-11)
\end{abstract}

Likewise, in the province of Quebec, the Conseil superieur de l'education (2000) has proposed a program to "introduce guidelines for a teacher training procedure ... to contribute to the professionalization of college-level teaching" (p. 1). In their brief to the Quebec Ministry of Education (College-Level Teacher Training, 2000), the Council stressed the urgent need for training among college teachers. In the words of Celine Saint-Pierre, president of the council, "while passion and mastery of the discipline taught are essential, they are not always enough. To truly support learning, and help students overcome the difficulties they encounter, requires specific competencies and knowledge acquired through initial and continuing teacher training" (p. 1). The Council's brief concludes with a recommendation "that it be compulsory for college teachers to add teacher training specific to the college level to qualifications related to their discipline" (p. 1).

In the province of Ontario, this need for pre-service preparation of college faculty is also being recognized and acted upon. A recent government review of post-secondary education, chaired by former Premier Bob Rae, noted that "quality also depends on excellence in teaching instruction .... There is, however, no systematic province-wide approach to teaching faculty how to teach" (Rae, 2005 , p. 10). One of the report's recommendations for "possible approaches to improving quality [is to] focus on teaching excellence [through] a Centre of Higher Education Teaching Excellence that could develop best practices for teaching, for both applied and academic subjects, [and] offer training and/or resources material, preparation, and ongoing support for the teaching role" (p. 
$60)$ in post-secondary institutions. In response to this call, Fanshawe College has developed a Graduate Certificate in College Teaching program (Rodgers, 2005; Rodgers \& Fisher, 2005) to ensure having "professors who are skilled educators, as well as subject experts" (Rodgers, p. 1). The envisioned program would:
build on the applicant's subject expertise ... by providing knowledge and skill in the area of adult learning/college teaching .... A full certificate program would ensure that new college teachers possessed the skills necessary to design good learning experiences in the college environment right from the start .... Hiring graduates of such a program would support teaching quality, ensuring that professors had a solid grasp of college teaching philosophy and practice from their first day in classes, and emphasize our focus on student success. (Rodgers, pp. 1-2)

Therefore, in the context of Canadian community colleges, with their clear emphasis on career-oriented education, and consequent staffing needs requiring instructors with extensive subject expertise but often lacking in teaching expertise, such professional pre-service training and certification programs could provide an innovative response to the challenge of "leading a renewed focus on the pre-eminence of teaching and teaching excellence" (Rae 2005, p. 58) at community colleges.

While such efforts are a source of optimism for those who envision a professional pre-service training and certification program for aspirants to the profession, at present the primary model for beginning faculty induction still relies upon the traditional mentor-protégé pairing of experienced and beginning faculty.

\section{Mentoring beginning faculty}

Taking its name from the wise old "Mentor" of Homer's Odyssey, the process of mentoring has long been recognized and utilized in post-secondary educational institutions as an in-house process for inducting beginning teachers through mentor-protégé pairings wherein experienced faculty act as advisors, coaches, or guides to help inexperienced faculty adjust to their new career environments. In Empowering the Faculty: Mentoring Redirected and Renewed, Luna and Cullen (1995) provide an extensive review of the mentoring literature, identify current issues, and suggest areas for further research. Referring to Daloz (1986), Luna and Cullen note that if "education is viewed as a transformational journey, then mentors can be seen as guides, and mentoring as processes of modeling, maintaining tradition, offering a map, conceptualizing, and providing a mirror" (p. 6). Luna and Cullen's work appears to have had a widespread impact in promoting and structuring formal mentoring programs; their lists of benefits (for protégés, mentors, and institutions) have reappeared, almost verbatim, in innumerable publications on mentoring (Penner, 2001; University of Toronto, n.d.; Bailey et al., 2004; Hopkins \& Grigoriu, 2005; Bailey, 2004; Fanshawe College, 2004).

However, rather than focusing on instructional skills, these traditional mentoring models function primarily as a socialization process for both individual and institutional participants. "Mentoring," write Luna and Cullen, 
citing Wilson and Elman (1990), "is simply the best method of passing along the norms, values, assumptions, and myths that are central to an organization's successful survival" (p. 11). As another example of the predominantly socializing nature of traditional faculty peer mentoring, the University of Southern Florida (2000) handbook for new faculty describes their Faculty Mentoring Program as follows:

Like others, our College has its own culture, a system with distinct structural features, role relations, informal system dynamics and environmental stresses and strains. You should not be left to discover this culture and navigate in it all by yourself. Rather than expecting you to achieve excellence in teaching, research and service entirely on your own, we have established a mentoring program .... But we benefit, too. After all, mentoring is the socialization of faculty members learning the rules of academe. (p. 1)

In this context, the acquisition of teaching skills by beginning faculty seems to be a secondary factor in the purpose and process of mentoring. For example, at the University of Toronto Faculty of Applied Science and Engineering, the Framework for Mentoring of New Faculty Members (n.d.), lists seven "benefits for new faculty" of which "advice on scholarship/teaching" (p. 1) is second from last. Therefore, while traditional faculty mentoring models continue to flourish on college campuses, their effectiveness to beginning teachers in terms of the acquisition of teaching skills is another area for further research.

Some researchers (Hargreaves \& Fullan, 2000) suggest that this traditional mentor-protégé model is actually counterproductive. In Mentoring in the New Millennium, Hargreaves and Fullan note that the "old model of mentoring, where experts who are certain about their craft can pass on its principles to eager novices, no longer applies" (p. 52). Although their research is not specifically focused on post-secondary educational institutions, their comments on mentoring relationships may find application at the college level:

If the school assumes the mentor always knows best, even about teaching strategies, innovative new teachers might quickly experience the mentor relationship as an oppressive one. Mentors may seem more like tormentors .... These times call for less hierarchical mentor relationships; everyone needs help, not just the incompetent teacher or the novice. (p. 53)

In their re-conceptualization of mentoring as "a means to a larger end - the creation of a strong, improvement-oriented profession" (p.55), Hargreaves and Fullan herald a new and promising model of mentoring which, along with preservice training and certification of beginning teachers, may inform the design of comprehensive programs of faculty development for community colleges in the new millennium. 


\section{Toward a Comprehensive Program of Faculty Development}

\section{The scholarship of teaching}

Much of the impetus toward a re-conceptualization of mentoring and faculty development has derived from Boyer's (1990) seminal work, Scholarship Reconsidered: Priorities of the Professoriate, which called for a re-emphasis on the "scholarship of teaching" (p. 23). "Community colleges," wrote Boyer, "have teaching as their central mission" (p. 60). Boyer refers to the Commission on the Future of Community Colleges (1988), which defined this goal precisely:

At the center of building community there is teaching. Teaching is the heartbeat of the educational enterprise and, when it is successful, energy is pumped into the community, continuously renewing and revitalizing the institution. Therefore, excellence in teaching is the means by which the vitality of the college is extended, and a network of intellectual enrichment and cultural understanding is built. (pp.7-8)

Hutchings and Shulman (1999), in The Scholarship of Teaching: New Elaborations, New Developments, further elaborate this theme:

The scholarship of teaching and the vision it embodies . . . have generated significant interest and activity in the last few years. There are, in short, now faculty - lots of them - who are eager to engage in sustained inquiry into their teaching practice and their students' learning, and who are well positioned to do so in ways that contribute to practice beyond their own classrooms. (p. 10)

In their "new elaborations" (p. 10) of Boyer's vision, Hutchings and Shulman (1999) propose the following definition:

The scholarship of teaching is not synonymous with excellent teaching. It requires a kind of "going meta," in which faculty frame and systematically investigate questions related to student learning - the conditions under which it occurs, what it looks like, how to deepen it, and so forth - and do so with an eye not only to improving their own classroom but to advancing practice beyond it .... The scholarship of teaching is a condition - as yet a mostly absent condition for excellent teaching. It is the mechanism through which the profession of teaching itself advances, through which teaching can be something other than a seat-of-the-pants operation, with each of us out there making it up as we go. (p. 13)

This call for a re-emphasis on teaching as the primary function of colleges in the new millennium has, unfortunately, not been fully heeded by college administrators. Murray (1999), in Faculty Development in a National Sample of Community Colleges, points out the urgent need for more serious attention to faculty development programs. Citing Schuster et al., Murray (1999) writes that colleges: 
for whatever reasons, have been neither sufficiently alert to the everchanging circumstance of their instructional staffs nor adequately resourceful in meeting their changing needs for professional development. It is indeed striking how much has been written about faculty growth and renewal, and how few campuses have seen fit to develop comprehensive, systematic programs. (p. 90)

Current faculty development programs, Murray continues, "are little more than a series of mostly voluntary, single-purpose isolated efforts, or a loosely related set of disparate activities [that] are unlikely to produce any real institutional change" (p. 49). In his extensive study of 130 American community colleges, Murray found "a glaring lack of commitment on the part of the leadership for faculty development" (p. 58). The colleges surveyed relied on "mix-and-match (perhaps mismatched) strategies [and] on a smorgasbord of activities rather than a unified plan with clear and coherent strategies based on articulated objectives" (p. 59). "The research," Murray concluded, "is almost unanimous on the ineffectiveness of such an approach" (p .61). O'Banion (1994) is similarly critical of "faculty development programs [which] varied immensely from short in-house workshops to summer institutes and retreats" (p. 3). Galbraith and Shedd (1990) provided yet another example of the urgent need for Building Skills and Proficiencies of the Community College Instructor of Adult Learner:

Opportunities for enhancing the instructional processes for all faculty are of paramount importance, if the community college is to experience effectiveness and meaningfulness in the process of teaching and learning. With the growing number of adult learners utilizing the offerings of the community college, it is obvious that all faculty should be engaged in a professional development plan that addresses the process of effective facilitation of adult learning. (p. 12)

The importance of further research into the re-conceptualization and implementation of appropriate faculty development programs cannot be understated. Fugate \& Amey (2000) stress the need for further research in their recent study of Career Stages of Community College Faculty: Qualitative Analysis of Their Career Paths, Roles, and Development. "Participants," they write:

saw faculty development programs as an important component of the ability to be effective teachers. Development activities were believed to be both a personal responsibility of continued professional improvement, and an institutional responsibility in supporting staff. . . . For those who select community college instruction as their career, it is seemingly critical that appropriate institutional instructional support be made available especially during the first year .... [Faculty] saw a direct link between their ability to teach and faculty development. (pp. $1,13,17,19)$

While the literature stresses the urgent need for more comprehensive development programs for both new and experienced faculty, there are 
indications that progress is underway. Especially promising is the emerging focus on the scholarship of teaching in the context of a community of scholars (Boyer, 1990, p. 80).

\section{Toward a community of scholars}

Beginning with Boyer's Scholarship Reconsidered (1990), new theoretical concepts have emerged that propose a collaborative mentoring model designed not only to induct individual faculty into the prevailing culture, but also to involve a wide spectrum of experienced faculty in collegial discussion aimed at improving the overall teaching/learning process within the institution (Boyer, 1990; Brookfield, 1995; Hargreaves \& Fullan, 2000). Boyer's report "focused largely on faculty members as individuals. But professors, to be fully effective, cannot work continuously in isolation. It is toward a shared vision of intellectual and social possibilities - a community of scholars - that . . . academic endeavor should lead. In the end, scholarship at its best should bring faculty together. A campus-wide, collaborative effort around teaching would be mutually enriching" (Boyer, p. 80). Boyer envisioned campuses where "faculty might work together to establish criteria for good teaching, be encouraged to move freely in and out of classrooms, observing colleagues and discussing their own teaching procedures" (p. 38). In particular, he mentioned, as exemplar, a program at Northwestern State University in Louisiana called "Teaching Circles" composed of "groups of five to seven faculty who voluntarily come together, with one member designated as leader. The goal is to focus exclusively on teaching. Those participating observe each others' teaching and together review classroom events" (p. 38).

Since Boyer's seminal work first popularized the term, Teaching Circles have proliferated across North American college campuses (Hutchings \& Shulman, 1999). Teaching circles are differentiated from traditional mentorprotégé models by their small group format, collaborative sharing, and primary focus on improving institutional teaching excellence rather than on individual induction. At Penn State University, for example, Teaching Circles "provide a rich opportunity for small groups of faculty members to work together on a topic pertaining to the improvement of teaching and learning. The aim . . is to build community and to foster collegiality by involving as many faculty as possible in collaborative efforts to improve teaching and learning at our college" (Penn State, n.d.). Research funded by the Hewlett Foundation at Nazareth College, in Rochester, New York, supports these results (Enerson, 2004). According to the National Education Association (2000), Teaching Circles are "important catalysts for change. The basic premise behind them: All faculty can learn from each other .... Many faculty, both newer and senior, are yearning for opportunities for good talk about good teaching" (p. 3). In support of this initiative towards promoting the scholarship of teaching in the context of a community of scholars, the Carnegie Institute has launched a "Teaching Academies" program, providing substantial funding to American and international post-secondary institutions which demonstrate a commitment to "1) foster significant, long-lasting learning for all students, 2) advance the practice and profession of teaching, and 3) bring to teaching the recognition afforded to other forms of scholarly work" (Hutchings \& Shulman, 1999). 
It is within this context that Hargreaves and Fullan (2000) have proposed their re-conceptualization of mentoring, based on developing "strong professional cultures of collaboration" (p. 51). "The challenge," write Hargreaves and Fullan, "will be to bring together the cultures of youth and experience. This will involve harnessing the energies that new teachers bring to the system, without marginalizing the perspectives and wisdom of teachers whose knowledge and experience have deep roots in the past" (p. 54). In their new theoretical model, mentoring is transformed "from being performed in pairs to becoming an integral part of professional cultures in schools; from hierarchical dispensations of wisdom to shared inquiries into practice; from being an isolated innovation to becoming an integrated part of broader improvement efforts to re-culture our schools" (p. 55). The goal "is not to create high-quality mentor programs as ends in themselves, but rather to incorporate mentoring as part and parcel of transforming teaching into a true learning profession" (p. 55). Although their research is not specifically focused on post-secondary educational institutions, the recommendations of Hargreaves and Fullan are congruent with similar reconceptualizations (Boyer, 1990; Hutchings \& Shulman, 1999) for postsecondary institutions, and suggest further opportunities for research in the context of Canadian community colleges.

\section{Conclusion: Research Opportunities at Community Colleges}

In articulating a scholarship of college teaching, this paper explored three critical research questions related to (a) effective college teaching practices, (b) preservice training of beginning teachers, and (c) in-house faculty development programs focused not only on inducting new faculty, but on raising the institutional level of excellence in teaching. These questions provide numerous opportunities for further research.

Regarding the first question, it was noted above that little research has been conducted into the qualities of effective teaching at Canadian community colleges. If colleges in the new millennium, with their clear mandate for careerrelated education, are to successfully meet the needs of students and the expectations of the employment community, then excellence in teaching must be the common driving force across all college disciplines. Currently, instruments developed to measure college teaching performance reflect criteria used in elementary and secondary settings, a situation which raises a number of questions for further study: What are the demographic characteristics and expectations of contemporary college students? Are the current measures of teacher performance, derived from elementary and secondary contexts, appropriate for adult learners? What exactly is the definition of effectiveness, and how should it be measured by student achievement, administrator or student teacher-rating scales, teacher self-efficacy surveys, or some yet undeveloped means?

Second, as thousands of beginning college teachers enter the profession, with little or no training as teachers, the need for pre-service training and certification requires urgent attention. In terms of accountability, how can the community college system, whose mandate is the training and certification to provincial standards of a professional workforce, continue to exempt their own faculty from the same expectations of professional training and certification? Programs such as Fanshawe College's Graduate Certificate in College Teaching provide further 
opportunities to conduct longitudinal studies into the effectiveness of pre-service training programs to meet the needs of all stakeholders, including beginning college teachers, administrators, and contemporary college students.

Finally, this paper examined the in-house induction programs currently used by post-secondary institutions, including both traditional mentor-protégé pairings and innovative Teaching Circles which are designed not only for the induction of new faculty, but also for the building of communities of scholars focused on institutional excellence in teaching. As this paper has demonstrated, numerous opportunities currently exist for scholarly research into the appropriateness of criteria currently used to measure effective college teaching, the development of pre-service training programs to prepare aspirants to the profession of college teaching, and the re-conceptualization of professional development programs in the development of communities of scholars. Such research could contribute to the development of a scholarship of college teaching which has current value and application for students, faculty, and administrators amid the challenges and changes sweeping through the classrooms and boardrooms of today's community colleges.

\section{References}

American Association of Community and Junior Colleges. (1988). Building communities: A vision for a new century. A Report of the Commission on the Future of Community Colleges. Washington, DC: National Center for Higher Education.

Apps, J. (1981). The adult learner on campus: A guide for instructors. Chicago: Follett.

Bailey, A.., Clement, D., Demers, P., Ledwell, P., McRobert, J., O'Kell, R., et al. (2004). The Academy as community: A manual of best practices for meeting the needs of new scholars. Ottawa, Canada: Canadian Federation for the Humanities and Social Sciences.

Boyer, E.L. (1990). Scholarship reconsidered: Priorities of the professoriate. Princeton, NJ: The Carnegie Foundation for the Advancement of Teaching.

Brookfield, S.D. (1995). Becoming a critically reflective teacher. San Francisco: Jossey-Bass.

College-level teacher training: A joint project involving the whole college community. (May, 2000). Quebec City, Quebec: Conseil superieur de l'education. Retrieved Feb. 23, 2005 from http://www.cse.qc.ca/e/pub/panorama/2000-05/College.htm.

Coulter, M.W. (January/March, 1993). Modern teachers and postmodern students. Community College Journal of Research and Practice, 17, 51-58.

Cruickshank, D.R., \& Haefele, D. (Feb. 2001). Good Teachers, Plural. Educational Leadership. 58(5), 26-30.

Daloz, L.A. (1986). Effective teaching and mentoring. San Francisco: Jossey-Bass.

Denzin, N., \& Lincoln, Y. (2005). The Sage handbook of qualitative research ( ${ }^{\text {rd }}$ ed.). Thousand Oaks, CA: Sage.

Enerson, D.M. (2004). Faculty collaboratives for teaching and learning: Interim report \#2. Rochester, NY: Nazareth College.

Engememann, J., \& Fisher, R. (2005). Measuring effectiveness of college mentoring programs. St. Catherines, Canada: Brock University SSHRC grant.

Faculty mentoring program (2000). University of Southern Florida. Retrieved Aug. 1, 2005, from http://www.cas.usf.edu/cas/facultyDevelopment/mentoring.htm.

Faculty peer mentor program guidelines. (2004). London, Canada: Fanshawe College.

Framework for the mentoring of new faculty members. (n.d.). Toronto, Canada: University of Toronto Faculty of Applied Science and Engineering. Retrieved Aug. 1, 2005, from http://www.ecf.toronto.edu/apsc/research/framework/mentoring.html.

Fugate, A.L., \& Amey, M.J. (Summer, 2000). Career stages of community college faculty: A qualitative analysis of their career paths, roles, and development. Community College Review, $28(1), 1-23$.

Galbraith, M.W. \& Shedd, P.E. (Fall, 1990). Building skills and proficiencies of the community college instructor of adult learners. Community College Review, 18(2), 6-15. 
Glaser, B.G., \& Strauss, A.L. (1967). The discovery of grounded theory: strategies for qualitative research. Chicago: Aldine.

Hargreaves, A., \& Fullan, M. (2000). Mentoring in the new millennium. Theory into Practice 39(1), 50-56.

Hawk, P.P., Coble, C.R., \& Swanson, M. (May-June 1985). Certification: It does matter. Journal of Teacher Education, 36 (3), pp.13-15. In Stronge, J.H. (2002). Qualities of effective teachers. Alexandria, Virginia: Association for Supervision and Curriculum Development, p. 106.

Higgins, C.S., \& Hawthorne, E.M. (Spring, 1994). The successful community college instructor: A profile for recruitment. Community College Review, 21(4), 27-37.

Hopkins, R.A., \& Grigoriu, E. (Spring, 2005). Mentoring community college faculty and staff: Balancing contradictions of informal program components and formal program structure. Community college review, 32(4), 40-60.

Hutchings, P. \& Shulman, L.S. (1999). The scholarship of teaching: New elaborations, new developments. Change 31(5), 10-15.

Johnson, B.L. (1977). An organizational analysis of multiple perspectives of effective teaching: Implications for teacher evaluation. Journal of personal evaluation in education, 11, 69-87). In Stronge, J.H. (2002). Qualities of effective teachers. Alexandria, Virginia: Association for Supervision and Curriculum Development, pp. 107-8.

Keim, M.C. (1989). Two-year college faculty: A research update. Community College Review, 17(3), 33-43.

Keim, M.C. (1994). Graduate preparation programs in community college education. Community College Review, 22(1), 53-61.

Lowry, C., \& Froese, W. (2001). Transitions: Becoming a college teacher. Paper presented at 2001 Pan-Canadian Education Research Agenda Symposium, May 22-23, 2001, Laval University, Quebec City, Canada.

Luna, G. \& Cullen, D.L. (1995). Empowering the faculty: Mentoring redirected and renewed. Washington, D.C: George Washington University.

McBer, H. (June, 2000). Research into teacher effectiveness: A model of teacher effectiveness. England: Department for Education and Employment, Research report \#216. In Stronge, J.H. (2002). Qualities of effective teachers. Alexandria, Virginia: Association for Supervision and Curriculum Development, p. 110.

Miller, A.A. (Spring, 1997). Eric review - back to the future: Preparing community college faculty for the new millennium. Community college review, 24(4), 83-93.

Murray, J.P. (Winter, 1999). Faculty development in a national sample of community colleges. Community college review, 27(3), 47-64.

National Association of Secondary School Principals. (May/June 1997). Students say: What makes a good teacher? NASSP bulletin, pp. 15-17. In Stronge, J.H. (2002). Qualities of effective teachers. Alexandria, Virginia: Association for Supervision and Curriculum Development, pp. 112-113.

O'Banion, T. (1994). Teaching and learning: A mandate for the nineties. Community college review, 64(4), 21-25.

Ontario Colleges of Applied Arts and Technology Act (2002). Toronto, Canada: Ministry of Training, Colleges, and Universities.

Ontario colleges face hiring crunch. (November 8, 2001). Retrieved November 10, 2004), from http:www.acaato.on.ca/new/pr/2001/hreng_nov08.html.

Overcoming the solitude of teaching (2000). National Education Association. Washington, DC. Retrieved Aug. 1, 2005, from http://www2.nea.org/he/advo00/advo0005/feature.html.

Penn State BKLV: Teaching and learning circles. (n.d.). Retrieved November 10, 2004, from http://www.bklv.psu.edu/faculty/circles.html.

Penner, R. (2001). Mentoring in higher education. Directions. Winnipeg, Canada.

Professor performance review program (2002). London, Canada: Fanshawe College.

Provincial instructor's diploma program (1999). British Columbia, Canada: B.C. Ministry of Skills, Training, and Labour.

Rae, R. (February 2005). Postsecondary review: Higher expectations for higher education: Report and recommendations. Toronto, Canada: Ministry of Training, Colleges, and Universities.

Rodgers, R. (2004). Teaching circles: Creating a community of practice among new teachers. London, Canada: Fanshawe College.

Rodgers, R. (2005). Request for permission to investigate: Graduate certificate in college teaching. 
London, Canada: Fanshawe College.

Rodgers, R. \& Fisher, R. (2005). Proposal for graduate certificate in college teaching. London, Canada: Fanshawe College

St. Clair, K. (Winter, 1994). Faculty to faculty mentoring in the community college: An instruction component of faculty development. Community College Review, 22, 23-26.

Stronge, J.H. (2002). Qualities of effective teachers. Alexandria, VA: Association for Supervision and Curriculum Development.

Van Ast, J., \& Mullen, E. (Winter,/Spring, 1999). The professional development of community college applied science and technology faculty. Journal of Technology Studies. 20(1), 1-12.

Wilson, J.A., \& Elman, N.S. (1990). Organizational benefits of mentoring. Academy of Management Executive, 4(4), 88-94. 